\title{
TOTAL DRAINAGE OF PULMONARY VEINS INTO THE RIGHT ATRIUM
}

\author{
BY \\ S. T. WINTER, E. N. EHRENFELD and J. FELDMAN \\ From the Hadassah University Hospital, Jerusalem, Israel
}

(RECEIVED FOR PUBLICATION JUNE 13, 1952)

\begin{abstract}
Anomalies of the pulmonary venous return are uncommon, particularly malformations with total drainage of the pulmonary veins directly into the right atrium. Brody (1942) reviewed the literature on anomalous pulmonary venous drainage, dealing with 106 cases, including four personal ones. Further necropsy reports have since been presented by Vass and Mack (1949) and Smith (1951), the latter also noting details of additional cases in the literature. Recent case reports by Johnson and McRae (1948), Dotter, Hardisty and Steinberg (1949), Knutson, Taylor, Pruitt and Dry (1950), Friedlich, Bing and Blount (1950), Grishman, Brahms, Gordon and King (1951), and Muller (1951) have dealt with patients diagnosed during life by means of angiocardiography and cardiac catheterization. Out of a total of 182 cases of anomalous pulmonary veins thus reported in the literature, 30 showed total anomalous drainage of the pulmonary veins into the right atrium or the coronary sinus.
\end{abstract}

The embryology of total pulmonary drainage into the right side of the heart has been discussed by Brody (1942) and by Brantigan (1947). Taussig (1947) has described fully its clinical aspects. The systemic circulation can only receive oxygenated blood from the right side of the heart via a patent foramen ovale. As the right side of the heart receives blood from both the systemic and pulmonary circulations, pulmonary congestion usually results from the excessive pulmonary blood flow. As suggested by Brody, decompensation in these cases presumably occurs with the gradual narrowing of the foramen ovale and the obliteration of the lumen of the ductus arteriosus, thus precipitating cardiac failure. The electrocardiogram is helpful, for there are few other congenital heart lesions without cyanosis and frequently without a murmur, showing right axis deviation on the electrocardiogram.

Partial anomalous venous drainage of the pulmonary veins is encountered occasionally in adults without symptoms, whereas total anomalous venous drainage is usually fatal in the first six months of life. Interest in this malformation, however, is increasing because of the possibilities of diagnosis during life and of surgical treatment. Muller (1951) has reported a successful operation on a 4-year-old girl with complete transposition of the pulmonary veins. Anastomosis between the left auricular appendage and pulmonary vein resulted in the disappearance of cyanosis and the ability to assume normal activities. Muller also performed a similar operation on an adult woman, but she died shortly afterwards. It is probable that earlier diagnosis by cardiac catheterization and angiocardiography will be needed for reparative surgery to be successful. Cardiac catheterization will show an oxygen content of the blood in the right auricle higher than that in the superior vena cava, and also the catheter may enter the pulmonary vein directly from the right auricle. The oxygen concentration of the blood in the femoral artery will be equal to that in the right side of the heart where there is total anomalous drainage, but will be higher if the anomalous drainage is only partial.

The following case, in which all four pulmonary veins entered the right atrium directly, presented the usual features of this malformation.

\section{Report of a Case}

A girl of Oriental Jewish parentage was admitted at the age of 10 weeks because of breathlessness.

The infant was born at full term after an uneventful pregnancy, appearing normal at birth, and weighing $2,100 \mathrm{~g}$. She was breast fed, and had been ill on several occasions with short bouts of fever and vomiting. The mother noticed that the child frequently had difficulty in breathing and sometimes even became blue. About 16 hours before admission the infant began to cough slightly and did not eat or sleep as usual. Four hours before admission she became distressed and cried 
repeatedly, cyanosis and shortness of breath becoming marked.

On examination she appeared to be a fairly well nourished infant, acutely ill, restless, cyanotic, crying out in distress and gasping for breath. The temperature was $37^{\circ} \mathrm{C}$., pulse rate 120 per minute, weight $3,900 \mathrm{~g}$. Breathing was rapid and shallow, mainly abdominal, with working of the alae nasi, tugging of the neck muscles and retraction of the lower ribs. The apex beat was heard in the fourth intercostal space $1 \mathrm{~cm}$. lateral to the left mid-clavicular line. Percussion showed the heart to be enlarged in all directions; the heart sounds were clear and the heart action rhythmic. On percussion there was some impairment of resonance at the right lung base posteriorly, with corresponding reduced air entry but without adventitious sounds. The liver edge was smooth and palpable about $3 \mathrm{~cm}$. below the right costal margin, and the spleen tip was felt under the left costal margin. The fingers were not clubbed.

A blood count gave: red cells, $4 \cdot 3 \mathrm{~m}$. per c.mm., haemoglobin, $10 \cdot 5 \mathrm{~g} . \%$, white cells, 11,400 per c.mm. The Mantoux reaction $(1: 1,000)$ was negative. A radiograph of the chest on admission showed an enlarged heart with clear lung fields.

The infant was given oxygen with a resultant slight improvement in respiration. On the following day she was apathetic and very restless. Cyanosis had increased, and breath sounds at both lung bases were further decreased. A faint systolic murmur was heard internal to the apex beat. The liver edge appeared to be $1 \mathrm{~cm}$. lower than on the previous day. A second radiograph (Fig. 1) showed an enlarged globular heart with poor

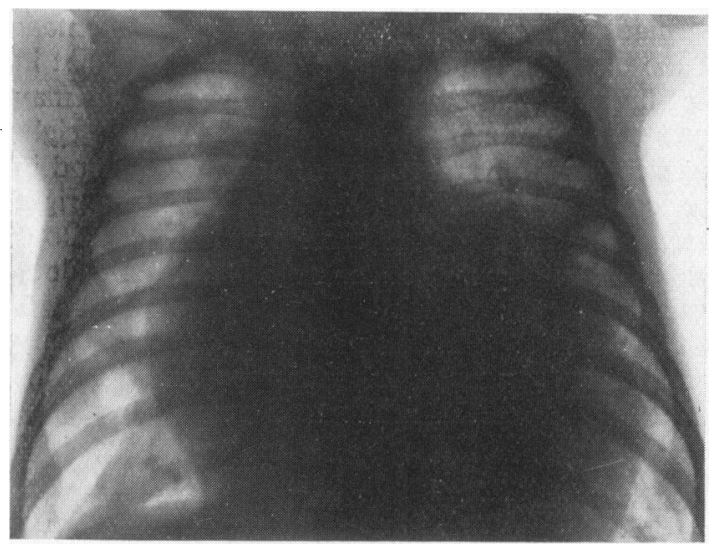

Fig. 1.-Chest radiograph.

pulsation, and reduced translucency of the right lung base and left mid-zone. On the third day in hospital she was much weaker, breathing in gasps. Dullness at the right base was more marked, and breath sounds were further reduced at both bases, especially at the right. Fluoroscopy was repeated and showed very slight heart pulsations, with a normal oesophageal outline on a barium swallow. Four hours later an E.C.G. was recorded, and the child died during this procedure.

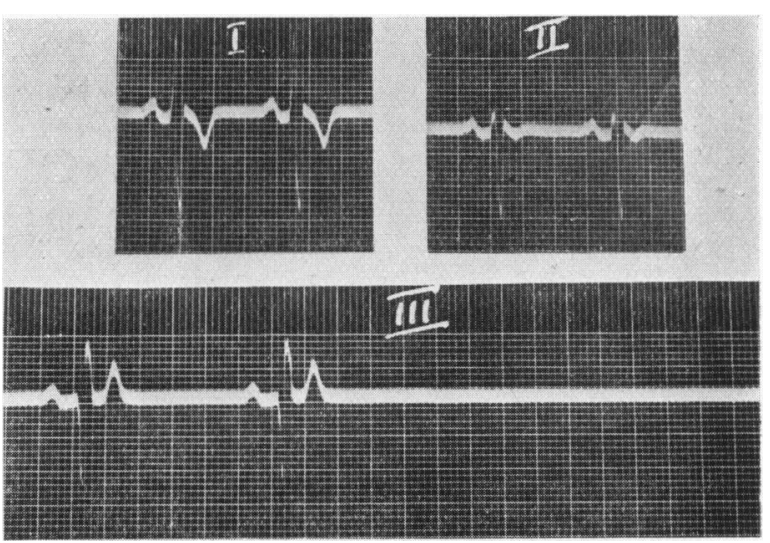

FIG. 2.-Electrocardiogram.

Electrocardogram REPORT. There were large bidirectional ventricular initial complexes with deep negative $T$ waves in lead $I$, large $Q$ waves and peaked positive $T$ waves in lead III (Fig. 2). There was extreme shortening of the Q-T interval before final asystole recorded in lead III.

NECROPSY REPORT. The principal abnormal findings were confined to the heart and lungs. All other organs were not unusual. The heart weighed $65 \mathrm{~g}$. The right atrium was markedly enlarged, and its lumen included that of the distended right auricular appendage. Its wall measured up to $3 \mathrm{~mm}$. in thickness. The right ventricle was enlarged with hypertrophy of its wall, and the tricuspid valve was not unusual. The left atrium was rudimentary, measuring about $1.5 \mathrm{~cm}$. in diameter. There was no entry of the pulmonary veins into the left atrium. Instead, all four pulmonary veins entered the posterior wall of the right atrium (Fig. 3). The right ventricle was approximately three times the size of the left ventricle, which was about normal in size for a baby of this weight and age. The papillary muscles were flattened or non-existent over most of the inner surface. The mitral valve was small, measuring $2 \mathrm{~cm}$. in circumference. The only communication between the right and left sides of the heart was through a patent foramen ovale with a lumen of approximately $2 \times 5 \mathrm{~mm}$. The pulmonary artery was enlarged, being larger than the aorta. The ductus arteriosus was still patent with a lumen of about $1 \mathrm{~mm}$. in diameter. The coronary arteries were not remarkable, originating in the usual anatomical position and taking a normal course. Several small haemorrhages were noted over the heart surface, particularly anteriorly.

Both lungs were covered with a thin transparent membrane, and were mottled externally red and blue. The blue regions were depressed and quite extensive. On section the same mottling was found. The cut surface was moist, spongy or haemorrhagic. The pulmonary vessels appeared enlarged, particularly the main branches.

Microscopic examination showed no significant changes in the body organs, with the exception of the 


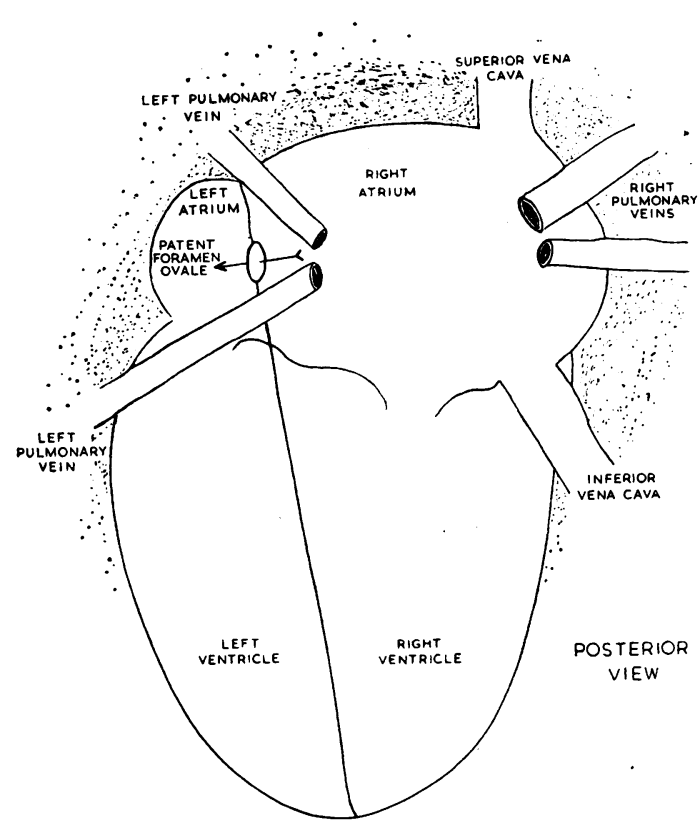

FIG. 3.-Scheme of posterior aspect of heart drawn at necropsy. liver, where congestion with fatty change was noted.

The pathological diagnosis was congenital heart disease; transposition of all pulmonary veins to the right atrium; a patent foramen ovale and a rudimentary left atrium; hypertrophy and enlargement of the right ventricle and right atrium; patent ductus arteriosus; pulmonary atelectasis.

\section{Summary}

A case of drainage of all pulmonary veins into the posterior wall of the right atrium is reported.

We wish to thank Professor B. Gruenfelder for permission to publish this report, and Dr. S. Berman and Dr. S. Shorr for their help.

\section{REFERENCES}

Brantigan, O. C. (1947). Surg. Gynec. Obstet., 84, 653.

Brody, H. (1942). Arch. Path. (Chicago), 33, 221.

Dotter, C. T., Hardisty, N. M. and Steinberg, I. (1949). Amer. J.

med. Sci., 218, 31. Hopk. Hosp., 86, 20. Grishman, A., Brahms, S. A., Gordon, A. and King, F. H. (1951).
J. Mt Sinai Hosp., 17, 336.

Johnson, A. L. and McRae, D. L. (1948). Pediatrics, 2, 643.

Knutson, J. R. B., Taylor, B. E., Pruitt, R. D. and Dry, T. J. (1950). Proc. Mayo Clin., 25, 52.

Muller, W. H. Jr. (195i). Ann. Surg, 134, 683.

Smith, J. C. (1951). Amer. Heart J., 41, 561.

Taussig, H. B. (1947). Congenital Malformations of the Heart.

Vass, A. and Mack, J. K. (1949). Amer. J. Dis. Child., 78, 906. 